\title{
Influence of the material volume of a lattice structure on bending properties
}

\author{
Katarina Monkova ${ }^{1,2^{*}}$, Peter Pavol Monka ${ }^{1,2}$, Oldřich Šuba ${ }^{2}$, Milan Žaludek ${ }^{2}$, Dražan \\ Kozak $^{3}$, and Jan Vanca ${ }^{1}$ \\ ${ }^{1}$ Technical University in Kosice, Faculty of manufacturing technologies, Presov, Slovakia \\ ${ }^{2}$ UTB Zlin, Faculty of technology, Vavreckova 275, Zlin, Czech Republic \\ ${ }^{3}$ University of Slavonski Brod, Mechanical Engineering Faculty, Slavonski Brod, Croatia
}

\begin{abstract}
The article deals with the experimental investigation of the influence of material volume of a lattice structure on bending stress. FDM (Fused Deposition modelling) technique and ABS (Acrylonitrile Butadiene Styrene) material were selected for the samples production. Three types of samples with the same simple lattice structure and the same size of a basic cell $5 \mathrm{~mm}$, but differ in a material volume ratio, were analysed experimentally. Minimally six pieces of the samples of each volume ratio were produced and tested using the ZWICK 1456 testing machine at an ambient temperature of $22{ }^{\circ} \mathrm{C}$ and at a relative humidity of $60 \%$ according to the standard EN ISO 604. The stress-strain diagrams have been plotted and the values of maximum stresses have been tabled. The measured data were statistically processed, and average values of bending stresses were calculated. Based on the results the behaviour of the structure has been mathematically described, while the results showed that the dependency has an exponential trend.
\end{abstract}

\section{Introduction}

In recent years, a few new fields which change the approach to life might be observed. Within the area of manufacturing, the most rapidly developing is additive manufacturing techniques. A special area of components that can be produced by the 3D printing technique is the socalled lattice structures, which are part of a family of so-called cellular materials. They have regular pore shapes and a periodic structure. [1] From a certain point of view, this lattice material is a three-dimensional (3D) reticulated foam with a special structure. The pore strut is connected and oriented according to certain rules in porous lattice materials, of which the pore has an identical shape and uniform size in the same porous body.

Compared to dense solid materials, cellular materials have low density, large specific surface area, good energy absorption, and greater specific strength and stiffness. Porous materials with different parameters and indices are used in various functional and structural applications; some of these can have both functions. There are many types of porous material, and the cell structures can take different forms with a wide range of pore sizes. [2,3]

\footnotetext{
* Corresponding author: katarina.monkova@tuke.sk
} 
Porous materials are used for structural purposes in some cases, and for functional purposes in other cases based on their different specific structural morphologies and properties. In some situations, they play a dual role of structure and function simultaneously. These types of materials can demonstrate comprehensive physical and mechanical properties. Therefore, porous materials can be used in the aerospace, electronics and communication, transportation, atomic energy, medical, environmental protection, metallurgy, machine, construction, electrochemistry, petrochemical, and bioengineering industries. This is due to their desirable capabilities, such as flow separation/filtration, distribution, sound absorption and noise reduction, dampening, electromagnetic screening, heat insulation and fire resistance, heat exchange, catalysis, electrochemical process and the medical plastic and repair. [4-7]

Due to the wide opportunity to use cellular materials in engineering practice, it is very important to know the behaviour of a specific lattice structure under load. The goal of the presented research has been to find out behaviour of a simple lattice structure under the bending load and to specify the dependency of the bending stress on the volume ratio of the porous structure.

\section{Materials and methods}

As it has been mentioned above, the lattice structure in the core of the product can give it a special combination of characteristics such are good strength, energy absorption, low weight at a good stiffness. Technique of FDM (Fused Deposition modelling) and plastics materials, type ABSplus (Acrylonitrile Butadiene Styrene)-P430 Ivory plastics were chosen for the manufacturing of specimens. The main reason of the selection was availability at the authors' workplaces, that was also motivated by less financial expenses in comparison with additive technologies for metal parts.

ABS belongs to the thermoplastic polymeric materials. As the name of ABS indicates, it consists of Acrylonitrile, Butadiene and Styrene polymers. It is widespread in large portion because it has very good plastic characteristics. It is lightweight, has good impact strength, resists abrasion, and is inexpensive. In addition, ABS polymers endure many chemical formulas. The melting temperature of ABS plastic is $200^{\circ} \mathrm{C}$, what is making it ideal for usage in relatively safe and easy-to-use machinery (e.g., in the household operating machines, at which the reliability is very important). [8] This is an ideal plastic for making cheap prototypes and architectural models for technicians or research workshops, as well as for making affordable medical prostheses or material handling gadgets. The natural characteristics of this material, such as its stiffness and strength, as well as its ability to resists to heat, make the material very suitable for various practical applications. It can also be applied into mechanical or electrical objects. In addition to its good mechanical properties and chemical resistance, the products made of ABS plastic have a good surface quality and they are fire retardant. Recently, there have been focuses on the ABS during 3D printing when it is brought to its melting point. In fact, some studies point that ABS gives off fumes when it leaves the extrusion head at its melting temperature. $[9,10]$

ABS is a material mainly used for plastics 3D printing within FDM (Fused Deposition modelling) or FFF (Fused Filament Fabrication) techniques. Material comes in the way of a long filament wrapped around a spool. A print head is used to apply a molten layer of plastic to the print bed, which then adheres. Once the first layer is pulled, the print bed lowers, and a new layer is built on top of the previous layer. This process is repeated several times, eventually resulting in a 3D printed model. The principle of the FDM technique is shown in Fig. 1a. Within the experimental investigation, 3D printer Prusa i3Mk2 was used for the samples manufacturing that is shown in Figure $1 \mathrm{~b}$. 
a)

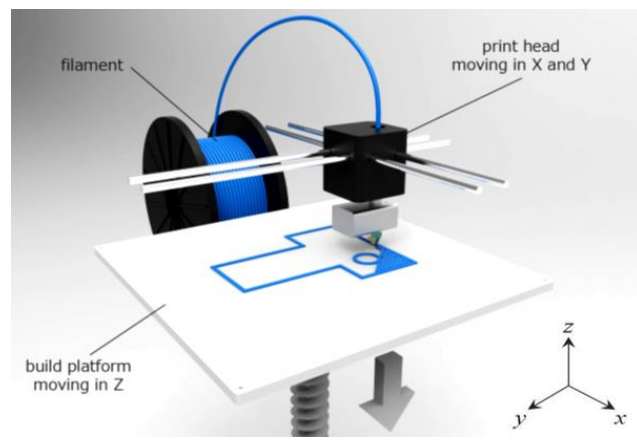

b)

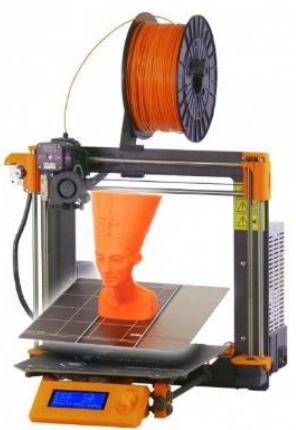

Fig. 1. a) The principle of FDM technique, b) 3D printer Prusa i3Mk2.

The next characteristics of the samples production are:

- filament diameter: $\phi 1.75 \mathrm{~mm}$,

- melting temperature of the filament: $300{ }^{\circ} \mathrm{C}$,

- nozzle temperature: $255^{\circ} \mathrm{C}$,

- temperature of the printing basement: $100{ }^{\circ} \mathrm{C}$,

- thickness of deposited layer: $0.254 \mathrm{~mm}$

- speed of solid infill: $40 \mathrm{mms}^{-1}$,

- $\quad$ speed at external perimeters: $30 \mathrm{mms}^{-1}$,

- building direction in 3D-printing corresponds to the $z$-axis,

- samples were printed without supports.

Three types of specimens, which differ only in the relative volume, were modelled, fabricated and tested. The outside shape of all specimens was designed in the tube form with a structure with outline sizes: diameter of $29 \mathrm{~mm}$ and length of $200 \mathrm{~mm}$, which were specified based on the requirements of the test apparatus. The thickness of the outer cylindrical full-material layer was $2 \mathrm{~mm}$. A simple Body-Centred Cubic (BCC) unit cell with dimensions of $5 \times 5 \times 5 \mathrm{~mm}$ with reinforced linear edges and a strut diameter of $1 \mathrm{~mm}$ was selected for this study. The basic cell was regularly distributed in all three axes of the rectangular coordinate system. The BCC basic cell, 3D model of a specimen with the corresponding structure prepared in software PTC Creo 7, and the basic dimensions of the sample are shown in Fig. 2. [11]
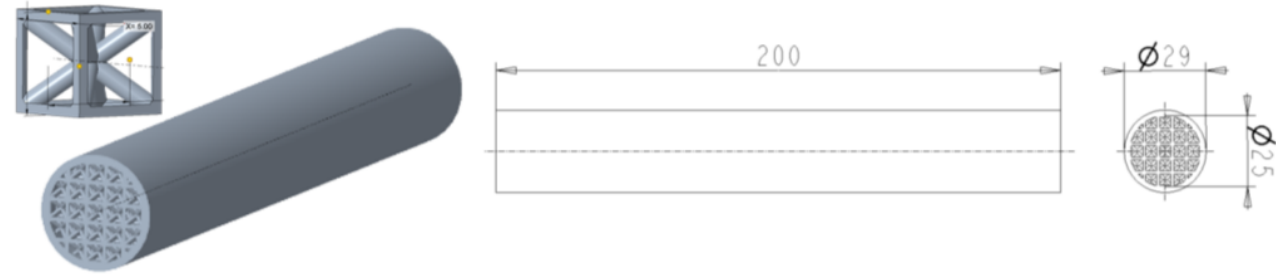

Fig. 2. Sample characteristics (from left - basic cell, 3D sample model, sample dimensions). [11]

Six samples were made from each 44; 57 and $70 \%$ volume ratio (18 samples in total) and tested experimentally. The volume ratio was controlled by the diameter of the base cell strut, which ranged from 1 to $2 \mathrm{~mm}$.

The bending tests were performed based on the standard EN ISO 604 while the testing machine ZWICK 1456 was employed. The experiments were done at ambient temperature of $22{ }^{\circ} \mathrm{C}$ and a relative humidity of $60 \%$. The extreme supports of the sample were spaced $170 \mathrm{~mm}$ apart and the push torn (with diameter $5 \mathrm{~mm}$ ) was positioned in the middle. The crossbeam feed rate during the tests was $20 \mathrm{~mm} / \mathrm{min}$. To be the results comparable, it was 
necessary to ensure the same position of all samples with vertically and horizontally oriented outer cubic struts of the lattice structure. $[11,12]$ The sample position at a testing machine at three points bending test and orientation of the structure in relation to a force load are presented in Fig. 3.
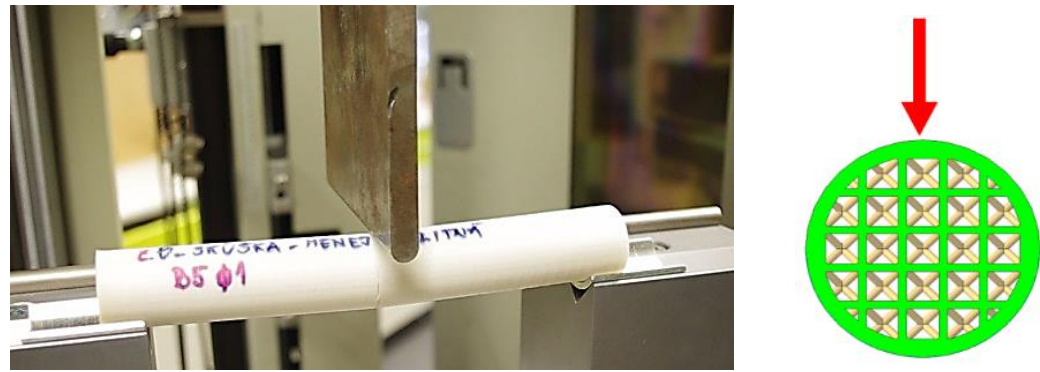

Fig. 3. The sample position at a testing machine and orientation of the structure in relation to a force.

\section{Results and discussion}

The bending behaviour of the samples was processed and plotted by means of TestXpert software. An example of obtained stress-strain curves for the samples with volume ratio $57 \%$ is in Figure 4.

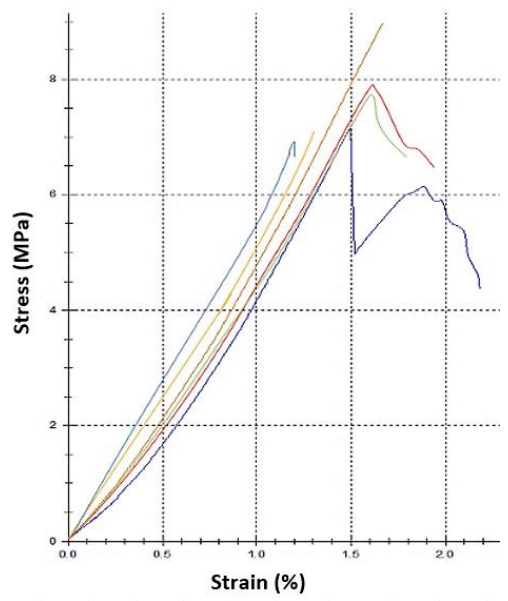

Fig. 4. Plotted stress-strain curves for the experimentally tested samples with $57 \%$ volume ratio.

The measured data were statistically processed, while outliers were excluded from the calculations, as shown in Table 1 in sample no. 1 with a $70 \%$ volume ratio. However, the software calculated stresses considering only the full volume cross-section area of the samples, which were the same at all samples (despite the different volume ratios). Due to this reason, the results were recalculated, while the precise cross-section areas were taking into account based on 3D models. The bending stresses were calculated using the equation (1)

$$
\sigma=\frac{F_{\max } l}{W o}=\frac{M o_{\max }}{W o}
$$

where $F_{\max }$ is maximal force; $l$ is the arm on which the force acts; $M o_{\max }$ is maximal bending moment; $\sigma$ is bending stress and $W_{o}$ is moment of inertia of the section area. 
Table 1. Measured and calculated data

\begin{tabular}{|c|c|c|c|c|c|c|}
\hline $\begin{array}{l}\text { Volume } \\
\text { ratio of a } \\
\text { sample } \\
(\%)\end{array}$ & $\begin{array}{l}\text { Sample } \\
\text { number }\end{array}$ & $\begin{array}{l}\text { Maximal } \\
\text { loading force } \\
F_{\max } \\
(\mathrm{N})\end{array}$ & $\begin{array}{c}\text { Bending } \\
\text { moment } \\
M_{\mathrm{O}} \\
(\mathrm{Nmm})\end{array}$ & $\begin{array}{c}\text { Moment of } \\
\text { inertia of the } \\
\text { section area } W_{\mathrm{O}} \\
\left(\mathrm{mm}^{3}\right)\end{array}$ & $\begin{array}{c}\text { Bending } \\
\text { stress } \\
\sigma_{\mathrm{O}} \\
(\mathrm{MPa})\end{array}$ & $\begin{array}{c}\text { Average } \\
\text { bending } \\
\text { stress } \sigma_{\mathrm{O}} \\
(\mathrm{MPa})\end{array}$ \\
\hline \multirow{6}{*}{44} & 1 & 259 & 11007.5 & \multirow{6}{*}{1212.29} & 9.08 & \multirow{6}{*}{$8.89 \pm 0.7$} \\
\hline & 2 & 273 & 11602.5 & & 9.57 & \\
\hline & 3 & 258 & 10965 & & 9.04 & \\
\hline & 4 & 232 & 9860 & & 8.13 & \\
\hline & 5 & 256 & 10880 & & 8.97 & \\
\hline & 6 & 244 & 10370 & & 8.55 & \\
\hline \multirow{6}{*}{57} & 1 & 372 & 15810 & \multirow{6}{*}{1352.12} & 11.69 & \multirow{6}{*}{$11.61 \pm 0.6$} \\
\hline & 2 & 366 & 15555 & & 11.50 & \\
\hline & 3 & 392 & 16660 & & 12.32 & \\
\hline & 4 & 360 & 15300 & & 11.32 & \\
\hline & 5 & 372 & 15810 & & 11.69 & \\
\hline & 6 & 355 & 15087.5 & & 11.16 & \\
\hline \multirow{6}{*}{70} & 1 & 344 & 14620.00 & & 9.48 & \multirow{6}{*}{$15.48 \pm 0.6$} \\
\hline & 2 & 577 & 24522.50 & \multirow{5}{*}{1542.77} & 15.90 & \\
\hline & 3 & 544 & 23120.00 & & 14.99 & \\
\hline & 4 & 572 & 24310.00 & & 15.76 & \\
\hline & 5 & 551 & 23417.50 & & 15.18 & \\
\hline & 6 & 566 & 24055.00 & & 15.59 & \\
\hline
\end{tabular}

Average values of bending stress for each volume ratio were computed and the dependence of the bending stress on the volume ratio was generated. The trend line has shown an exponential character that is described by the equation (2) with statistical reliability of " $\mathrm{R}$ square" coefficient $\mathrm{R}^{2}=0.9996$ that means the dependence is significant and functional:

$$
y=3.4656 e^{0.0213 x}
$$

The dependence of the average bending stress on the volume ratio for the studied specimens with BCC lattice structure is presented in Figure 5.

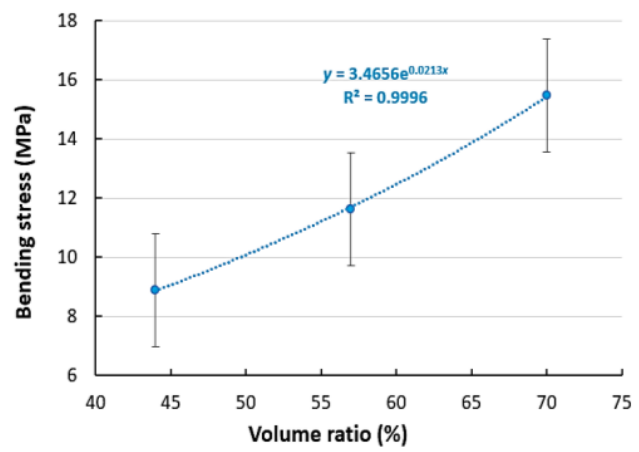

Fig. 5. The dependence of the average bending stress on the volume ratio.

Based on the measured and calculated data, it is not clear whether the dependence is really exponential or polynomial, so in the future, the authors will engage in similar research, in which samples with multiple volume ratios will be tested. 


\section{Conclusions}

To conclude the presented research, it can be said that the achieved results can form the basis for the design of components whose implementation in technical equipment reduces the overall weight of the system, saves material needed to manufacture such a component and maintains its mechanical properties and operational reliability specified by the designer.

- In this study, bending tests were performed to determine the behaviour of cylindrical specimens with a lattice structure and a BCC basic cell made by an additive approach from ABS plastic material.

- Three-point bending tests were performed and the bending stress of samples with three different volume ratios of $44 ; 57$ and $70 \%$ was evaluated in the present research.

- The trend curve indicated that the dependence of the bending stress on the volume ratio is not linear, but in order to accurately determine the bending behaviour of the porous structure, it will be necessary to perform further tests with the samples of different volume ratios.

The article was prepared thanks to support of the Ministry of Education, Science, Research, and Sport of the Slovak Republic through the grants APVV-19-0550 and KEGA 005TUKE-4/2021.

\section{References}

1. L. P. Lefebvre, J. Banhart, D. C. Dunand, Porous metals and metallic foams: current status and recent developments, Adv Eng Mat, 10, 9 (2008)

2. M. Montemurro, G. Bertolino,; T. Roine, A general multi-scale topology optimisation method for lightweight lattice structures obtained through additive manufacturing technology, Composite structures, 258 (2021)

3. G. Pantazopoulos, A. Vazdirvanidis, Fractographic and Metallographic Study of Spalling Failure of Steel Straightener Rolls, J of fail anal and prev, 8, 6 (2008)

4. Liu PS. Introduction to porous materials. Beijing: Tsinghua University Press (2004)

5. B. J. Yang, Z. P. Xi, H. P. Tang, Q. B. Wang, Research progress in preparation and application of gradient-porous metal, Powder Met Indus, 18, 2 (2008)

6. A. G. Mamalis, et al. Fabrication of multi-layered steel/superconductive ceramic (Y Ba $\mathrm{KCu} \mathrm{O}$ )/silver rods by explosive powder compaction and extrusion, Journal of Materials Processing Technology, 57, 1-2 (1996)

7. Cosma, C.; Drstvensek, I.; Berce, P. et al. Physical-Mechanical Characteristics and Microstructure of Ti6Al7Nb Lattice Structures Manufactured by Selective Laser Melting, Materials, 13, 18 (2020)

8. V. Utyaganova, A. Filippov, S. Tarasov, et al. Characterization of AA7075/AA5356 gradient transition zone in an electron beam wire-feed additive manufactured sample Materials characterization, 172 (2021)

9. M. Pollak, M. Torokova, M. Kocisko, Utilization of Generative Design Tools in Designing Components Necessary for 3D Printing Done by a Robot, TEM Journaltechnology education management informatics, 9, 3 (2020)

10. D. Bourell, J. Pierre, M. Leu, G. Levy, D. Rosen, A. M. Beese, A. Clare, Materials for additive manufacturing. CIRP Ann. Manuf. Technol, 66 (2017)

11. K. Monkova, et al. A Bending Test of the Additively Produced Porous Sample, 5th Int. Conf. on the I4.0 Model for Adv. Man. Lecture Notes in Mech. Eng. (2020)

12. M. Mulle, R. Zitoune, et al., Embedded FBGs and 3-D DIC for the stress analysis of a structural specimen subjected to bending, Composite Structures, 91, 1, (2009) 